\title{
A LUTA PELOS DIREITOS CIVIS NOS ESTADOS UNIDOS
}

\author{
Wilton Bruno Cardoso da Silva ${ }^{1}$
}

RESUMO: O presente artigo tem como objetivo elaborar uma análise a respeito dos principais eventos que marcaram a luta pelos direitos civis nos Estados Unidos durante a segunda metade do século XX, propondo uma reflexão sobre a importância do tema de estudo nos dias atuais e apontando as principais mudanças na legislação norte-americana visando o combate à desigualdade e discriminação racial no país. Com relação à atuação do Movimento dos Direitos Civis entre décadas de 1950 e 1960, destacar as principais dificuldades enfrentadas por seus líderes civis durante as campanhas no sul do país; enfatizando suas principais motivações e sua relevância, mesmo após décadas, no atual cenário político dos Estados Unidos e na sociedade internacional. Através de pesquisas feitas com embasamento em artigos científicos, livros e jornais, ressaltar a influência exercida mais de meio século após os eventos em destaque no artigo na formação e atuação de diversos movimentos sociais ao redor do mundo.

Palavras-Chave: Direitos Civis. Discriminação Racial. Estados Unidos.

\section{INTRODUÇÃO}

A primeira parte desse artigo focará na atuação do Movimento dos Direitos Civis dos negros nos Estados Unidos entre os anos de 1955 e 1963; na segunda parte, trataremos sobre os acontecimentos do ano de 1968 e o motivo pelo qual esse ano foi tão simbólico para o avanço dos movimentos sociais nos Estados Unidos. O intuito da pesquisa é mostrar os principais eventos que precederam o combate à discriminação racial no país. Com destaque nas campanhas ocorridas em Montgomery (1955-1956) e em Birmingham (1963), passando pelos conflitos e divergências entre o governo norte-americano e os movimentos sociais durante o ano de 1968, demonstraremos, por meio de pesquisas feitas com embasamento teórico, a importância e influência que o movimento dos direitos civis, mesmo após se passarem décadas dos acontecimentos tratados neste artigo, exerce nos dias

\footnotetext{
I Bacharel em Relações Internacionais pelo Centro Universitário Internacional - UNINTER. Lattes: http://lattes.cnpq.br/676298926583838o.E-mail: wilton_brunno_@hotmail.com/wbo899cs@gmail.com.
} 
atuais. A aprovação da lei dos direitos civis do ano de 1964 e a abolição da segregação em transportes coletivos em Montgomery também serão tratadas no decorrer da pesquisa, assim como a ascensão de grupos radicais e a crescente insatisfação popular com a atuação do governo durante os conflitos com o Vietnã no final dos anos 60.

Tendo obras de autores como Mark Kurlansky e Luther King como base referencial, analisaremos os principais atos promovidos pelo movimento dos direitos civis dos negros nos Estados Unidos. Enfatizando a importância do papel de líderes civis como Martin Luther King Jr. e Rosa Parks no combate a segregação racial, enraizada principalmente no sul do país.

\section{O Movimento dos direitos civis dos Negros}

2020 foi um ano que certamente ficará marcado na história dos EUA. Milhares de cidadãos norte-americanos foram às ruas em atos de protestos contra a atuação da polícia local em casos de abordagens a jovens negros (BBC, 2020). Diante dos avanços das mídias sociais qualquer pessoa conectada à internet pode ter acesso instantâneo aos acontecimentos de qualquer lugar do mundo. Rapidamente imagens desses protestos nos começaram a ganhar grande destaque na mídia internacional. Diversas manifestações antirracistas ocorreram em vários países do mundo em apoio ao povo afro-americano. No entanto, esse não foi o primeiro e provavelmente não será o último conflito dessa magnitude ocorrido nos Estados Unidos. Os protestos pelos direitos civis começaram a ganhar força ainda nos anos cinquenta, com o movimento dos direitos civis dos negros.

No dia 18 de dezembro de 1865 a escravidão foi finalmente abolida dos estados unidos, porém, mesmo com a aprovação da $13^{\underline{a}}$ emenda a realidade do negro nos Estados Unidos estava longe de se manter em pé de igualdade social com os demais norteamericanos. Apesar da abolição da escravidão, os estados mantinham uma política fortemente discriminatória de acordo com suas próprias legislações. Principalmente na região sul do país, o cidadão afro-americano era inferiorizado, marginalizado e limitado pelos governos e autoridades a sobreviver no mais baixo nível social. As comunidades mais pobres eram em sua maioria compostas por populações negras. Mesmo passados quase cem anos após o início da Guerra Civil Americana (186I-I865), ainda nos anos 
cinquenta, os afro-americanos conviviam com as mais diversas e escancaradas formas de discriminação que existiam no país. A mentalidade segregacionista no sul do país influenciava de maneira significativa as leis da época.

Mesmo em pleno século XXI, não é muito difícil imaginar uma situação em que um cidadão é colocado nos mais baixos níveis socias por conta da cor de sua pele. Por mais que volta e meia nos deparemos com casos de grande repercussão envolvendo discriminação racial (sem contar os que sequer ganham atenção da mídia nacional e internacional), nos anos cinquenta, a situação dos negros nos EUA beirava o caos.

A pobreza assolava os bairros de predominância afro-americana. A proporção de desemprego entre a população negra e branca era duas vezes maior, enquanto o salário duas vezes menor. As elites mais conservadoras ainda mantinham políticas discriminatórias nas legislações estaduais. Desde o nascimento, o negro era separado dos demais. Eram obrigados a frequentar ambientes "próprios para pessoas de cor". Restaurantes, hospitais, igrejas, e mesmo sendo pagadores de impostos, até mesmo eram limitados de frequentar alguns locais públicos que eram frequentados por pessoas brancas. (King, 1964). Diante desse cenário, vários líderes civis e religiosos começaram a se unir em prol do combate as leis de segregação racial. Ainda no começo do século, a National Association for the Advancement of Colore (NAAPC) já atuava pelos direitos civis do povo afro-americano. O movimento dos direitos civis viria a iniciar suas atividades nos Estados Unidos alguns anos depois. No entanto, foi em dezembro de 1955, com um ato de boicote aos ônibus na cidade de Montgomery, que o movimento dos direitos civis dos negros começou a ganhar notoriedade.

\footnotetext{
Quando Rosa Parks se recusou a ceder seu lugar ao homem branco, ela não tinha ideia de que sua ação isolada iria iniciar o boicote aos ônibus da cidade que duraria um ano inteiro, e que pode ser apontado como o ponto de partida para o Movimento dos Direitos Civis.” (PAIVA,2010, p.104)
}

Com a prisão de Rosa Parks, uma jovem costureira e ativista pelos direitos civis em Montgomery, que foi detida após se recusar a ceder seu lugar em um ônibus para um homem branco no dia Io de dezembro de 1955 , já que as leis locais obrigavam os cidadãos negros a cederem seus acentos quando os ônibus estivessem lotados. Após ser libertada, Rosa se uniu a o jovem pastor evangélico Martin Luther King Jr., e juntos com outros 
ativistas, começaram as manifestações pedindo pelo fim da discriminação nos transportes públicos nos estados do sul do país (UOL, 202I).

Após mais de um ano o Boicote aos ônibus de Montgomery (1955-1956), o movimento pelos direitos civis dos negros finalmente conseguiu uma de suas primeiras e mais significativas vitórias. Em 13 de novembro de 1956, a suprema corte revogou a lei local, tornando inconstitucional a discriminação de negros nos transportes coletivos. Um ato que foi um verdadeiro pontapé inicial para o avanço do movimento dos direitos civis, dando início ao surgimento de diversas manifestações posteriores pelo fim do sistema discriminatório na legislação dos estados norte-americanos.

Tanto o boicote quanto a decisão da suprema corte de revogar a lei de discriminação nos transportes coletivos geraram uma certa repercussão na imprensa local. Luther king então, unindo-se ao Pastor Fred Shuttlesworth e outros líderes do movimento dos direitos civis e pastores locais, começaram a planejar novas campanhas. Uma das mais conhecidas ocorreu na populosa cidade de Birmingham, Alabama, no ano de 1963. Paiva (2010) ressalta três aspectos que seriam motivo de destaque em futuros atos organizados pelos líderes do movimento dos direitos civis.

a. os negros de Montgomery foram capazes de unir todas as lideranças locais logo após a prisão de Rosa Parks, quando criaram a associação chamada Montgomery Improvement Association - MIA;

b. os atores que surgiram como líderes do boicote estavam propondo novas estratégias de resistência ativa e ação não violenta como forma de protesto; $\mathrm{e}$ c. as decisões tomadas no processo mostram que a comunidade negra não se dispunha a ceder ou a aceitar alguma solução inócua como era usualmente proposta pelos líderes brancos sulistas" (PAIVA, 2010, p.ro5)"

Fred Shuttlesworth e Luther king lideraram os protestos em Birmingham. mostrando seus ideais pacifistas e sua forma de combater a discriminação racial através de atos de desobediência civil. No entanto, houveram diversas retaliações pelas autoridades locais, já que boa parte dos líderes políticos e empresários locais eram declaradamente opositores a abolição das políticas discriminatórias do estado. Não demorou muito para que prisões começassem a ocorrer de forma avassaladora. Assim como espancamentos a jovens estudantes universitários, bombardeios, incêndios em igrejas e uso desenfreado da força policial durante as manifestações em Birmingham. Os próprios Fred Shuttlesworth e Luther King foram presos algumas vezes. (KING,1964). 
Durante abril de 1963, após o início dos protestos que ocorreram por toda Birmingham naquele ano, rapidamente a polícia respondeu de maneira brutal, utilizando mangueiras de incêndio, cães, cacetetes e gás lacrimogêneo para conter os manifestantes, resultando em centenas de prisões e feridos durante os conflitos. Rapidamente Imagens dos protestos em Birmingham começaram a rodar em todo o país. Fotos da brutalidade e violência policial com os manifestantes foram alvo de destaque nacional (BBC,2013).

As manifestações do ano de 1963 ficaram marcadas na história dos Estados Unidos, colocando Luther King como principal de liderança no combate à discriminação racial no país. A participação dos veículos de comunicação também um papel fundamental, já que, diante da repercussão em Birmingham, imagens dos protestos liderados por King rodaram o mundo. (PEREIRA,2019) destaca a contribuição dos veículos de comunicação durante as manifestações na década de 1960. Outros fatores-chave para se compreender as rebeliões desencadeadas nessa época
se devem ao desenvolvimento de meios de comunicação - a televisão, em
especial, passou a conectar espectadores de regiões de todo mundo - e do
modernismo em si, que atraiu os mais jovens para mobilizações em prol da
mudança social e política." (PEREIRA,2019, p.38).

Nesse mesmo período, vários jornalistas relataram sofrerem perseguições e tentativas de censura, até mesmo há relatos de ameaças por partes das autoridades locais. Embora a campanha em Birmingham fosse a mais dificultosa de sua carreira, Luther King acreditava que ela poderia ser bem sucedida e mudar radicalmente o modelo discriminatório que imperava não só em Birmingham, mas em todo o país. E através de um discurso pacifista, mostrar ao mundo que, mesmo após um século de libertação da escravidão, o negro americano ainda estava preso às raízes do segregacionismo (KING, 1963).

Cada vez mais cidadãos afro-americanos saíam as ruas em busca de melhores condições sociais. O movimento dos direitos civis estava próximo da sua principal conquista na suprema corte, ganhando cada vez mais popularidade, King liderou a conhecida Marcha sobre Washington em agosto daquele mesmo ano. Diante de centenas de milhares de pessoas, fez o histórico discurso intitulado 'I have a dream", cravando seu nome na história como uma das principais figuras na luta contra a segregação racial nos Estados Unidos. 


\section{A Lei dos Direitos Civis de 1964}

Ainda no ano de 1963, o então presidente Jorge F. Kennedy (1917-1963), apesar de declaradamente se opor às manifestações, fez um pronunciamento declarando seu apoio as pautas defendidas pelo movimento dos direitos civis. Ganhando apoio de alguns líderes do movimento, Kennedy colocou em pauta a proposta da lei que mais tarde ficaria conhecida por ter dado fim as "Leis Jim Crow”. No entanto, após o assassinato de Kennedy em 22 de novembro do mesmo ano, o projeto teve continuidade dada pelo presidente Lyndon B. Johnson (1908-1973).

No ano de 1964, após anos de conflitos e perseguições aos líderes civis e estudantes negros, a lei dos direitos civis era assinada por Johnson, uma grande vitória obtida depois de quase uma década de protestos e conflitos com as legislações estaduais, a lei de 1964 acarretou em uma radical mudança na legislação americana, decretando o fim da discriminação racial em espaços públicos e comerciais. Um ano mais tarde, foi aprovada uma emenda com base na mesma lei, garantindo a população afro-americana o direito ao voto $(\mathrm{BBC}, 2020)$.

\section{Os conflitos do ano de 1968}

Apesar de alguns líderes civis como Luther King e Rosa Parks ganharem destaque com a marcha sobre Washington e o boicote aos ônibus em Montgomery, estabelecendo-se como principais representantes do Movimento dos Direitos Civis, nem todos os ativistas da comunidade afro-americana compactuavam com os mesmos modos operandi, vários movimentos com uma postura mais reacionária também nesse mesmo período. A criação do Partido dos Panteras Negras e o separatismo e nacionalismo negro defendido por Malcom X começaram a ganhar uma certa notoriedade na época, com ideais revolucionários, ambos criticavam a postura pacifista de líderes como Luther King. De acordo com Elbaum (2018): "As trajetórias políticas de Malcolm X e de Martin Luther King, figuras centrais na evolução do radicalismo dos anos 1960, foram ao mesmo tempo elementos motores e reflexos das transformações ideológicas em curso."

A ideia de que o pacifismo de Luther King não funcionaria por muito tempo em uma sociedade tão segregada quanto a norte-americana começou a ser discutida de uma 
maneira mais recorrente, o que se intensificaria após o assassinato de Luther King ano de I968 e os diversos conflitos que ocorreriam ao redor do mundo naquele mesmo ano. Segundo Pereira (2019): 'O ano de 1968 é compreendido como um divisor de águas nas formas como os movimentos sociais se organizam e se difundem".

De acordo com Silva (20II), o ano de 1968 seria o início de uma revolução tecnológica, política e social, que permearia até os dias de hoje. A França se tornaria palco de uma revolta estudantil. Pedindo por melhores condições para trabalhadores e melhorias no sistema educacional francês, o movimento estudantil francês entrou em diversos conflitos com as autoridades policiais. Pouco tempo depois, uniram-se a classe operária e começaram uma série de manifestações em busca de mudanças no sistema social e econômico do país, posteriormente se espalhando por todo o território europeu.

Nos Estados Unidos, os eventos ocorridos no final da década de 1960 e início da década de 1970 causaram verdadeiras oscilações na sociedade norte-americana. Assim como os movimentos de Birmingham e Montgomery poucos anos antes, os movimentos no final da década de i96o transformaram os Estados Unidos no epicentro das manifestações populares. O país estava no meio do confronto com o Vietnã. Em janeiro de 1968, ocorreria o primeiro de uma série de ataques Vietnamitas as bases norte-americanas no país, que posteriormente ficaram conhecidas como Ofensiva do Tet. A insatisfação popular com a intervenção militar no Vietnã era cada vez maior, tanto que após os ataques de 3I de janeiro, os movimentos socias organizaram-se em campanhas por todo o país. A adesão popular às manifestações contra a guerra gerou uma certa instabilidade no sistema político norte-americano. Se por um lado a aprovação do governo Johnson era cada vez menor, por outro, os movimentos civis ganhavam cada vez mais popularidade, inclusive influenciando na derrota de Johnson nas eleições de 68. Assim como na França, o movimento estudantil norte-americano organizou diversas campanhas pelo campus das universidades. As campanhas pelo fim da discriminação com grupos minoritários, a oposição à guerra, e o posicionamento abertamente contra o sistema elitista e conservador norte-americano foram os principais fatores responsáveis pela ascensão de diversos grupos durante as décadas de 1960 e 1970. O Movimento Hippie surge ainda no começo dos anos 6o, contestando o modelo capitalista e o estilo de vida consumista dos norte-americanos. Com influência das campanhas promovidas pelo movimento dos direitos civis nos anos 5o, 
o Movimento Black Power inicia suas atividades no final dos anos 60 junto com o Black Panther Party (Partido dos Panteras negras).

\begin{abstract}
Em ambos os contextos, o movimento de 1968 - que apesar da data, se inicia muito antes e torna-se um resultado explosivo de reivindicações ao longo da evolução do Movimento Negro - foi capaz de chamar a atenção para o descontentamento de camadas da sociedade que não mais aceitariam as estruturas discriminatórias. A adesão da população afrodescendente aos movimentos e protestos foi incremental para a força do movimento e, em ambos os contextos, muitas mudanças foram conquistadas não só a nível legal do Estado, mas também social e cognitivo: o negro se entende como negro e reivindica os espaços que historicamente lhe foi negado ou limitado; tem orgulho de seu cabelo, de sua música e de sua cultura e passa a desafiar as estruturas que buscaram lhe marginalizar durante toda sua existência.” (PEREIRA, 2018, p. 56)
\end{abstract}

Com o assassinato de Luther King em abril daquele ano, o movimento negro norteamericano se dividiu ainda mais. Os atos de desobediência civil organizados pelo movimento dos direitos civis nos anos 50 foram substituídos por rotineiros conflitos armados entre ativistas e policiais.

\title{
CONSIDERAÇÕES FINAIS
}

As campanhas promovidas pelo movimento dos direitos civis deram início ao combate a todo um sistema de repressão contra grupos minoritários nos Estados Unidos. Desde o início dos atos organizados pelo do movimento dos direitos civis nos anos 50 até os conflitos da década de 70 diversas mudanças políticas e sociais ocorreram no ao redor do país. Com a vitória na suprema corte em Montgomery e a aprovação da lei dos direitos civis de 1964 o movimento dos direitos civis ganhou cada vez mais apoio popular. Os atos de desobediência civil promovidos na época, antes vistos como simples atos vandalismo e desacato às autoridades locais, tornaram-se um sinônimo de luta por igualdade em todo o país; assim como reação das autoridades durantes as campanhas em Birmigham e Washington também influenciaram diretamente no surgimento de uma vertente mais radical do movimento negro norte-americano nos anos seguintes, ocasionando em conflitos que permeariam até o início dos anos 80 .

Conclui-se, então, que atuação dos movimentos sociais nos Estados Unidos durante a segunda metade do século $\mathrm{XX}$ não apenas influenciaram diretamente no fim das leis discriminatórias dos estados do sul, como também na formação e atuação de vários outros 
movimentos sociais que surgiram posteriormente. É evidente que, mesmo após décadas de conflitos entre grupos sociais e o governo norte-americano, casos de discriminação acontecem diariamente no país. No entanto, mais de meio século após as campanhas em Montgomery, Birmingham e Washington, o debate em volta dos direitos civis continua atual na sociedade internacional.

\section{REFERÊNCIAS}

ANDREWS, G. R. O negro no Brasil e nos Estados Unidos. Lua Nova: Revista de Cultura e Política, São Paulo, vol.2 no.I, June 1985. Disponível em: <https://www.scielo.br/pdf/ln/v2nt/ar3v2nr.pdf > Acesso em: o8 de Set. 2020.

BRYANT, N. Martin Luther King e o violento protesto que nunca aconteceu. BBC News, Nova York, 2013. Disponível em: https://www.bbc.com/portuguese/noticias/2013/o8/130826_martin_luther_manifestacao_n b_cc_gm Acesso em: io de Dez. 2020.

ELBAUM, M. 1968: explosão e transformação da corrente radical nos Estados Unidos. Revista Movimento, São Paulo, 2018. Disponível em: <https://movimentorevista.com.br/2018/o6/1968-estados-unidos-movimento-negropanteras-negras-guerra-vietna/> Acesso em: 03 de Jan. 202I.

KING, M.L. Por que não podemos esperar. Faro Editorial; São Paulo, Iํㅡㄹ. ed, 2020.

KURLANSKY, M. 1868 O ano que abalou o mundo. Editora José Olímpio; ${ }^{\mathrm{a}}$ ed. RJ, 2005.

PAIVA, A.R., Movimento dos direitos civis: esfera religiosa em movimento social. Centro Edelstein, p.I-I4, 2010. Disponível em: http://books.scielo.org/id/3wsmq/pdf/paiva-9788579820410-o6.pdf > Acesso: Fev. 202I.

PEREIRA, M. M., O MOVIMENTO NEGRO E AS REVOLUÇÕES DE 1968: UMA ANÁLISE DA RELAÇÃO E RESSIGNIFICAÇÃO DO NEGRO E O HISTÓRICO DO MOVIMENTO NO BRASIL. Revista Movimentos Sociais e Dinâmicas Espaciais, Recife, V. 8, N. I, 2019, P.34-57. Disponível em: https://periodicos.ufpe.br/revistas/revistamseu/article/view/240135/32922 >Acesso em: Jan.202I 
SANCHES, M. Morte de George Floyd: as semelhanças entre 2020 e o histórico ano de 1968 nos EUA. BBC News, Washington, 2020. Disponível em: https://www.bbc.com/portuguese/internacional-52904253 > Acesso em: I8 de Dez. 2020.

SILVA, D. N. Rosa Parks; Brasil Escola. Disponível em: https://brasilescola.uol.com.br/biografia/rosa-lee-parks.htm > Acesso em: o8 de Jan. 202I.

SILVA, D. N. Maio de 1968. Brasil Escola. Disponível em: https://brasilescola.uol.com.br/historiag/maio-1968.htm Acesso em: 08 de Jan. 2021. 